\title{
Prevalence of thinness using new international cut-off points among Santal tribal children and adolescents of Purulia District, West Bengal, India
}

\author{
Subal Das ${ }^{1}$, Kaushik Bose ${ }^{2}$ \\ Sri Lanka Journal of Child Health, 2011; 40(3): 105-110 \\ DOI: http://dx.doi.org/10.4038/sljch.v40i3.3507
}

\begin{abstract}
Objectives: A community based cross-sectional study was undertaken to determine the prevalence of undernutrition using body mass index (BMI) among 7-18 year old Santal children and adolescents of Purulia District, West Bengal, India.
\end{abstract}

Methods: A total of 421 (217 boys) children from ten villages was measured. Age and sex specific new international BMI $\left(\mathrm{kg} / \mathrm{m}^{2}\right)$ based cut off values were used to evaluate nutritional status.

Results: Although girls had greater mean weight and BMI than boys, these sex differences were not statistically significant. Moreover, boys and girls had almost similar mean heights. Although more girls $(44.6 \%)$ than boys $(38.3 \%)$ were undernourished, this sex difference was also not significant. The overall prevalence of thinness $(41.3 \%)$ was very high among the studied Santal children and adolescents.

Conclusion: The children and adolescents of both sexes were observed to be under serious and critical nutritional stress.

(Key words: Thinness; BMI; boys; girls; Santal; undernutrition)

\section{Introduction}

Childhood and adolescence are stages of rapid growth and final maturity of human development. Physical growth of an individual continues through childhood and ends at adolescence. The nutritional status of children and adolescents contributes significantly to the health status of the community. Whilst India celebrates its booming economy and

Department of Anthropology, Vidyasagar University, Midnapore, West Bengal, India

(Received on 27 August 2010: Accepted the revised version on 24 September 2010) gross domestic product (GDP) growth, the country remains one of the most malnourished in the world today. Prevalence of malnutrition is still nearly double that reported in many countries in subSaharan Africa.

Although the problem of undernutrition is pervasive across the whole of India, national aggregates mask wide disparities between different groups. For example, rates are highest amongst scheduled tribes and castes, $54 \%$ being stunted. Child malnutrition in rural areas is also much higher $(51 \%$ stunting and $46 \%$ underweight) than in urban areas (40\% children are stunted and $33 \%$ underweight). Similarly while $60 \%$ children from the poorest quintiles are stunted, $50 \%$ children in the middle income quintiles are stunted (NFHS III, $)^{1}$. India presents a typical scenario of South-Asia, fitting the adage of 'Asian Enigma', where progress in childhood malnutrition seems to have sunk into an apparent undernutrition trap, lagging far behind other Asian countries characterized by similar levels of economic development ${ }^{3-6}$. As per latest census, India has more than 84 million tribals who constitute $8.2 \%$ of the total population ${ }^{7}$. India probably has more tribal communities than anywhere else in the world ${ }^{8}$.

There is scanty information on nutritional status of tribal children and adolescents using the new internationally accepted body mass index (BMI) cutoff values, particularly from rural areas in India. Therefore, there is a need to develop a database on the nutritional status of the children and adolescents, using these cut-off values from different parts of the country to enable government and non-governmental agencies to formulate policies and initiate strategies for the well-being of children and adolescents. During the last two decades, anthropometric measurements have become the measures of choice for determination of nutritional status among children and adolescents. It is now well established that the BMI is the most appropriate, inexpensive, noninvasive tool to determine nutritional status ${ }^{9}$. In this paper, an attempt has been made to assess the current 
nutritional status, using new international cut-off values, of Santal tribal children and adolescents of Purulia district, West Bengal, India.

\section{Methods}

The present cross-sectional and community based study was conducted in ten different villages of Purulia district situated about $250 \mathrm{~km}$ from Kolkata city, the provincial capital of West Bengal. It was carried out from December 2009 to January 2010. The estimated sample size was calculated to be 329 by the formula: $n=(z 2 p q) / d 2$, where $z=1.96, p$ is the prevalence of malnutrition $(30 \%)$ in children and adolescents from age 7 to 18 years, $q=1-p$ and $d$ is the desired precision $(5 \%)^{10}$. A total of 421 (boys $=$ 217) children and adolescents was included in the present study. Age of the subject was considered to the nearest whole number. Thus, the appropriate (to the nearest whole age) cut-off values were utilized.

Data was collected after obtaining the necessary approval from the village and block authorities and parents were informed about the objectives before the commencement of measurement. The ethical committee of the Department of Anthropology, Vidyasagar University, West Bengal, India approved the data schedule. Purulia has its boundaries on the east with Paschim Medinipur and Bankura districts of West Bengal; on the north with Bardhaman district of West Bengal; on the north-west, west and south-west with Jharkhand state. According to the report of West
Bengal Scheduled Castes and Tribes Facts and Information, Special Series No. 32, 1989, Santals, among all the tribal communities of Purulia district, comprise $62.66 \%$ of the population. Tribal societies of Purulia are having distinct characteristics, where most of them are of Proto-Australoid group with dark skin colour, sunken nose and lower forehead. Information on age, gender, weight and height was collected on a pre-tested questionnaire by house-tohouse visit following interview and examination. Anthropometric measurements such as height and weight were made by a trained investigator (SD) following the internationally accepted standard techniques $(\mathrm{WHO})^{9}$. Height and weight measurements were recorded to the nearest $0.1 \mathrm{~cm}$ and $0.5 \mathrm{~kg}$ respectively. The BMI was computed using the following formula:

$\mathrm{BMI}=$ Weight $(\mathrm{kg}) /$ Height $\left(\mathrm{m}^{2}\right)$

The BMI was used to evaluate the nutritional status of the subjects ${ }^{10}$. BMI cut-off points were followed to define thinness. The age and sex specific cut off values were established based on international surveys ${ }^{11,12}$. The subjects were selected through simple random sampling method in all ten villages. Student's t-test and ANOVA test were used to test for sex and age differences in weight, height and BMI. All statistical analyses were performed using the SPSS statistical package. Statistical significance was set up to $\mathrm{p}$ value less than 0.05 .

Table 1: Mean \& standard deviation of weight, height \& BMI of 7-18 years Santal children and adolescents

\begin{tabular}{|c|c|c|c|c|c|c|}
\hline \multirow{2}{*}{$\begin{array}{c}\text { Age } \\
\text { (Years) }\end{array}$} & \multicolumn{3}{|c|}{ Boys } & \multicolumn{3}{|c|}{ Girls } \\
\hline & Weight (kg) & Height (cm) & BMI $\left(\mathrm{kg} / \mathrm{m}^{2}\right)$ & Weight (kg) & Height (cm) & BMI $\left(\mathrm{kg} / \mathrm{m}^{2}\right)$ \\
\hline 7 & $18.70 \pm 2.17$ & $115.00 \pm 6.12$ & $14.11 \pm 0.71$ & $17.73 \pm 1.81$ & $114.27 \pm 4.89$ & $13.56 \pm 0.93$ \\
\hline 8 & $20.87 \pm 1.97$ & $121.20 \pm 4.94$ & $14.20 \pm 0.91$ & $20.90 \pm 3.58$ & $121.47 \pm 7.11$ & $14.08 \pm 1.33$ \\
\hline 9 & $22.22 \pm 3.27$ & $123.73 \pm 7.69$ & $14.47 \pm 1.25$ & $24.09 \pm 4.16$ & $127.36 \pm 7.47$ & $14.75 \pm 1.44$ \\
\hline 10 & $25.22 \pm 4.63$ & $130.52 \pm 9.16$ & $14.68 \pm 1.16$ & $25.71 \pm 4.18$ & $132.34 \pm 7.33$ & $14.59 \pm 1.19$ \\
\hline 11 & $27.14 \pm 3.34$ & $134.46 \pm 7.19$ & $14.98 \pm 0.94$ & $28.00 \pm 4.24$ & $135.79 \pm 7.65$ & $15.09 \pm 0.89$ \\
\hline 12 & $32.25 \pm 5.34$ & $140.74 \pm 7.65$ & $16.17 \pm 1.53$ & $33.82 \pm 5.92$ & $141.21 \pm 9.77$ & $16.78 \pm 1.57$ \\
\hline 13 & $34.78 \pm 7.13$ & $146.92 \pm 8.65$ & $15.93 \pm 1.70$ & $33.46 \pm 8.85$ & $140.50 \pm 12.17$ & $16.54 \pm 2.14$ \\
\hline 14 & $42.85 \pm 5.13$ & $155.00 \pm 5.73$ & $17.78 \pm 1.31$ & $39.97 \pm 5.25$ & $147.36 \pm 6.21$ & $18.35 \pm 1.66$ \\
\hline 15 & $43.79 \pm 4.93$ & $156.76 \pm 5.65$ & $17.78 \pm 1.32$ & $37.38 \pm 4.72$ & $144.61 \pm 5.73$ & $17.89 \pm 2.18$ \\
\hline 16 & $48.07 \pm 5.94$ & $156.89 \pm 3.45$ & $19.50 \pm 1.98$ & $41.40 \pm 8.08$ & $147.39 \pm 8.02$ & $18.93 \pm 2.32$ \\
\hline 17 & $46.00 \pm 4.90$ & $159.55 \pm 5.12$ & $18.04 \pm 1.16$ & $49.12 \pm 6.03$ & $153.15 \pm 3.91$ & $20.89 \pm 1.86$ \\
\hline 18 & $49.75 \pm 5.69$ & $160.31 \pm 5.70$ & $19.31 \pm 1.36$ & $39.16 \pm 3.68$ & $147.67 \pm 4.62$ & $17.93 \pm 1.17$ \\
\hline
\end{tabular}




\section{Results}

Table 1 presents the mean and standard deviations of weight, height and BMI by age and sex. The overall mean (standard deviation) of age, weight, height and BMI were 11.32 (3.47) years, $29.91(10.75) \mathrm{kg}, 134.7$ $(15.62) \mathrm{cm}$ and $15.87(2.36) \mathrm{kg} / \mathrm{m}^{2}$, respectively. Girls (mean $=30.25 \mathrm{~kg}$; SD $=10.36$ ) and boys (mean $=29.59 \mathrm{~kg} ; \mathrm{SD}=11.11$ ) had similar mean weight. Both sexes had similar mean height (boys: mean = $134.80 \mathrm{~cm}, \mathrm{SD}=16.82$; girls: mean $=134.50 \mathrm{~cm}, \mathrm{SD}$ $=14.28)$. Mean BMI was also similar in both sexes (boys: mean $=15.63 \mathrm{~kg} / \mathrm{m}^{2} ; \mathrm{SD}=2.10$; girls: mean $=$ $16.12 \mathrm{~kg} / \mathrm{m}^{2} ; \mathrm{SD}=2.59$ ).
The prevalence of thinness (among boys and girls) of the Santals of Purulia, West Bengal, is shown in Table 2. From this table it can be inferred that, in general, both sexes had similar levels of thinness (boys $=38.2 \%$; girls $=44.6 \%$ ). However, among girls, the prevalence of Grade III and Grade II thinness was higher than in boys (Girls: Grade III = 4.4\%, Grade II $=13.7 \%$, Grade I $=26.5 \%$; Boys: Grade III $=2.3 \%$, Grade II $=6.5 \%$, Grade I $=$ $29.5 \%$ ). However, there was negative significant sex difference in mean BMI $(\mathrm{t}=-2.144, \mathrm{p}<0.05)$ observed i.e. girls have more mean BMI values than boys except for the ages $7,8,10,16$ and 18 years. The overall (sex-combined) prevalence of thinness $(41.3 \%)$ was very high among the studied Santal children and adolescents.

Table 2

Percentage distribution of nutritional status based on age and sex of the studied sample

\begin{tabular}{|c|c|c|c|c|c|c|c|c|c|c|}
\hline \multirow{2}{*}{$\begin{array}{c}\text { Age } \\
\text { (Years) }\end{array}$} & \multicolumn{5}{|c|}{ Boys } & \multicolumn{5}{|c|}{ Girls } \\
\hline & $\mathbf{n}$ & $\begin{array}{c}\text { Thinness } \\
\text { Grade- } \\
\text { I }\end{array}$ & $\begin{array}{c}\text { Thinness } \\
\text { Grade- } \\
\text { II }\end{array}$ & $\begin{array}{c}\text { Thinness } \\
\text { Grade- } \\
\text { III }\end{array}$ & Normal & $\mathbf{n}$ & $\begin{array}{c}\text { Thinness } \\
\text { Grade- } \\
\text { I }\end{array}$ & $\begin{array}{c}\text { Thinness } \\
\text { Grade- } \\
\text { II }\end{array}$ & $\begin{array}{c}\text { Thinness } \\
\text { Grade- } \\
\text { III }\end{array}$ & Normal \\
\hline 7 & 27 & 44.4 & 7.4 & 0.0 & 48.1 & 31 & 32.3 & 22.6 & 9.7 & 35.5 \\
\hline 8 & 39 & 25.6 & 10.3 & 2.6 & 61.5 & 21 & 38.1 & 9.5 & 4.8 & 47.6 \\
\hline 9 & 23 & 30.4 & 4.3 & 8.7 & 56.5 & 27 & 25.9 & 11.1 & 3.7 & 59.3 \\
\hline 10 & 32 & 43.8 & 6.2 & 3.1 & 46.9 & 17 & 47.1 & 17.6 & 0.0 & 35.3 \\
\hline 11 & 14 & 35.7 & 7.1 & 0.0 & 57.1 & 09 & 44.4 & 0.0 & 0.0 & 55.6 \\
\hline 12 & 18 & 16.7 & 11.1 & 0.0 & 72.2 & 11 & 9.9 & 0.0 & 9.1 & 81.8 \\
\hline 13 & 09 & 22.2 & 11.1 & 11.1 & 55.6 & 13 & 0.0 & 23.1 & 0.0 & 76.9 \\
\hline 14 & 13 & 7.7 & 0.0 & 0.0 & 92.3 & 19 & 21.1 & 0.0 & 0.0 & 78.9 \\
\hline 15 & 17 & 23.5 & 0.0 & 0.0 & 76.5 & 17 & 11.8 & 23.5 & 5.9 & 58.8 \\
\hline 16 & 07 & 0.0 & 0.0 & 0.0 & 100.0 & 15 & 3.3 & 20.0 & 6.7 & 60.0 \\
\hline 17 & 06 & 66.7 & 0.0 & 0.0 & 33.3 & 08 & 12.5 & 0.0 & 0.0 & 87.5 \\
\hline 18 & 12 & 16.7 & 8.3 & 0.0 & 75.0 & 16 & 43.8 & 18.8 & 6.2 & 31.2 \\
\hline Total & 217 & 29.5 & 6.5 & 2.3 & 61.8 & 204 & 26.5 & 13.7 & 4.4 & 55.4 \\
\hline
\end{tabular}

\section{Discussion}

The BMI, which is considered as an index of chronic energy deficiency (CED), is not constant in growing children and adolescents. Successive waves of NFHS data brings to the fore widespread undernutrition among Indian children, although in some instances, they show a declining trend during the inter survey period. Nevertheless, the latest estimates, as provided by the NFHS $3^{1}$, highlight the continuance of high overall levels of child malnutrition in India. The prevalence of child undernutrition in India varies widely across the states and also across rural and urban areas. Malnutrition among children and adolescents is a serious public health problem internationally, especially in developing countries. The recent study of Cole et $\mathrm{al}^{11}$ has stated that undernutrition is better assessed as thinness (low 
BMI for age) than as wasting (low weight for height). Prior to this report, there were no suitable thinness cut-offs for 2-18 years age group ${ }^{11}$. The uses of these new cut-off points are suggested to encourage direct comparison of trends in childhood thinness and overweight/obesity worldwide. Moreover, these cutoffs provide a classification of thinness for public health purposes at the national level. Based on our study, the prevalence of thinness among Santal children and adolescents of Purulia clearly indicated that the nutritional situation was very poor with $41.3 \%$ of overall thinness. Girls were thinner (44.6\%) than boys $(38.2 \%)$. The limitations of our study were the small sample size and the population being a mono-ethnic group.

Figures 1 (a) and (b) present the overall comparison of the mean weight $(\mathrm{kg})$ of the 7-10 years old of the present study with reference data ${ }^{13}$. It is clear from the figures that Santal children were lighter (both boys and girls) than the WHO reference data ${ }^{13}$. Figures 2 (a) and (b) present the overall comparison of the mean of height $(\mathrm{cm})$ of the 7-10 years old present study with reference data ${ }^{13}$. It is again clear from the figures that Santal children were shorter (both boys and girls) than the reference data ${ }^{13}$.

Figures 3 (a) and (b) present the overall comparison of the mean of BMI $\left(\mathrm{kg} / \mathrm{m}^{2}\right)$ of the $7-10$ years old of the present study with reference data ${ }^{13}$. It is clear from the figures that Santal children were more likely to grow into thin adults with a low BMI than reference data ${ }^{13}$. This might have an impact on their physical status and rates of morbidity and mortality.
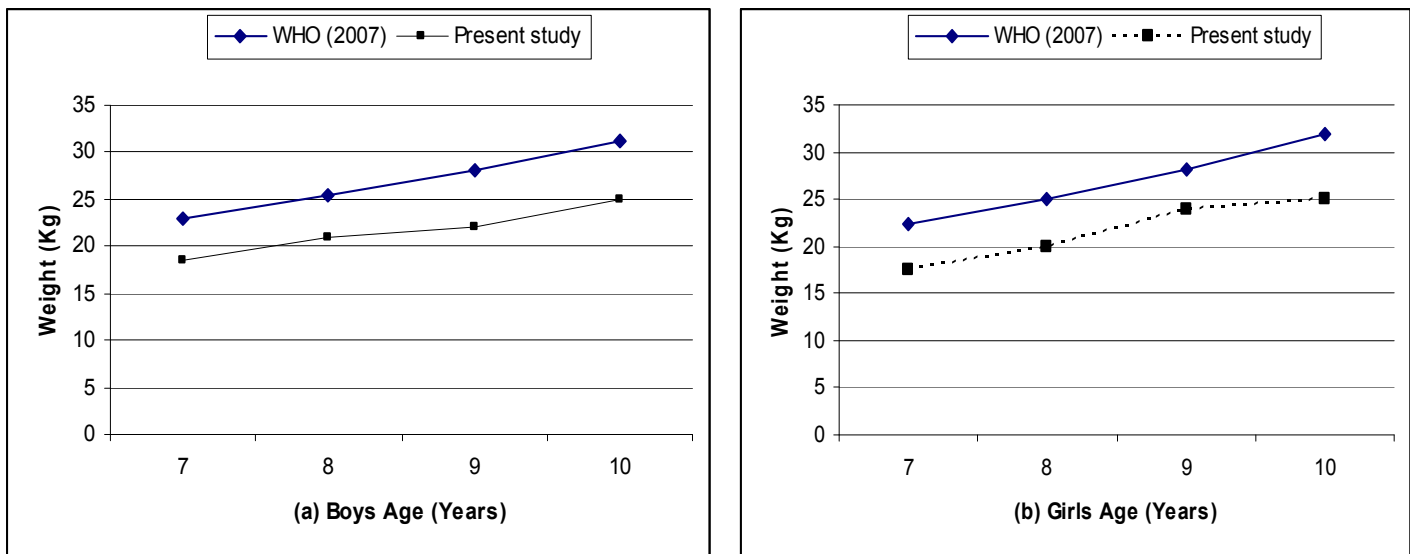

Figures 1 (a) and (b): present the mean weight (kg) of the WHO (2007) and the present study
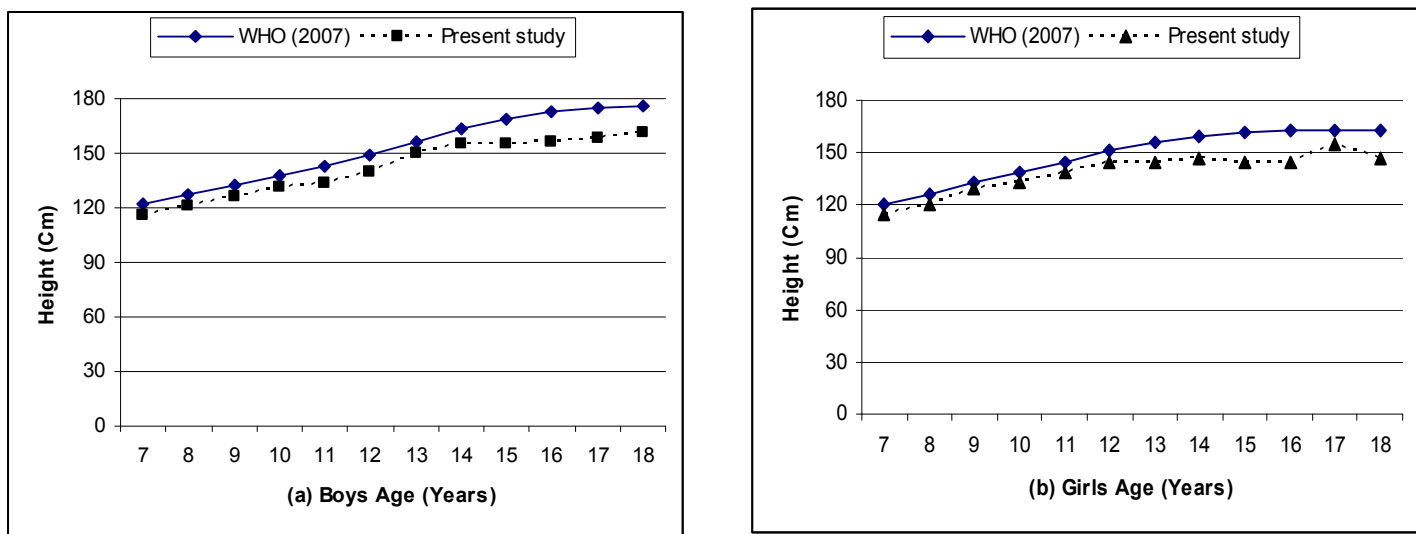

Figures 2 (a) and (b): present the mean height $(\mathrm{cm})$ of the WHO (2007) and our study 

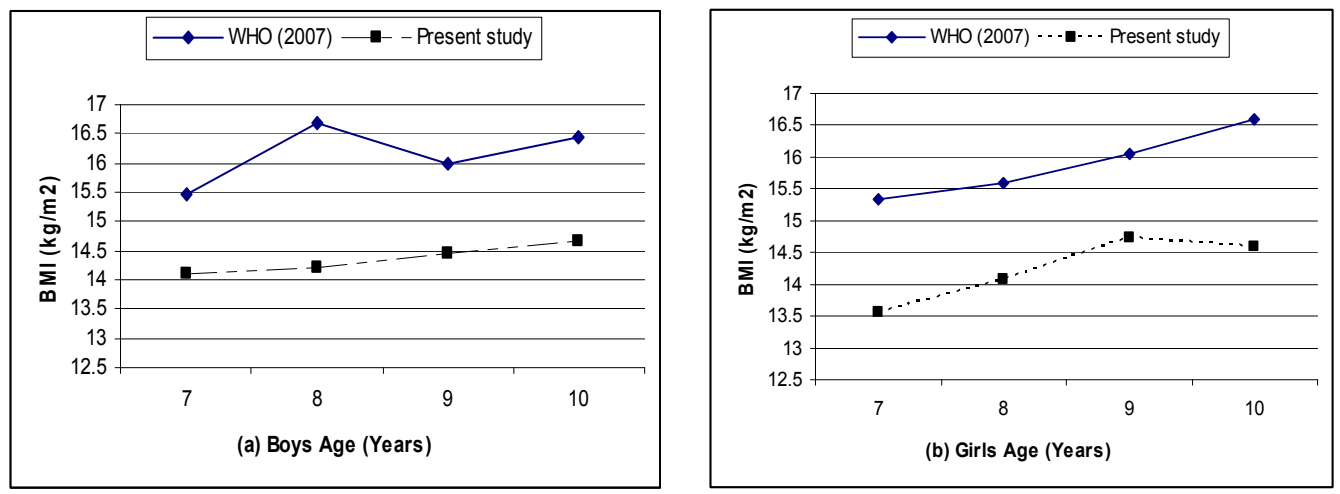

Figures 3 (a) and (b) present the mean BMI $\left(\mathrm{kg} /{ }^{\mathrm{m} 2}\right)$ of the WHO (2007) and our study

A previous study ${ }^{14}$ using the same international cutoff values among school children of Bankura reported lower prevalence of thinness $(23.1 \%)$. Other studies using these cut-off values among the school children of Paschim Medinipur \& Purulia ${ }^{15}$, Purba Medinipur $^{16}$ and Dibrugarh ${ }^{17}$ have reported higher prevalence of $44.5 \%, 62.2 \%$ and $50.2 \%$ thinness, respectively, than the present study $(41.3 \%)$.

Thus the present study revealed that the nutritional status of the Santal children and adolescents of these villages was in serious or critical situation. To overcome this problem more state specific policies should be designed on a priority basis, to arrest the level of undernutrition and improve the nutritional status of children and adolescents. Such measures would help them in achieving their maximum growth potential.

Lastly, it must be mentioned here that one of the major strengths of our study was that thinness was evaluated using the new internationally accepted BMI cut-off points. Very few studies in India have done that.

\section{Conclusions and recommendations}

Santal children and adolescents of both sexes in Purulia, West Bengal, India, were observed to be under serious and critical nutritional stress. In the Indian context, we also suggest that similar studies be undertaken amongst other ethnic children and adolescents, especially in rural areas, to determine the prevalence of thinness using these new international cut-off points. Such studies would help in generating new data which can be used for national and global comparisons. Appropriate health promotion and nutritional intervention policies can be formulated based on the findings of these investigations.

\section{Acknowledgements}

All participating subjects, villagers and block authorities are gratefully acknowledged for their cooperation. Subal Das received financial assistance in the form of Junior Research Fellowship from University Grants Commission, Government of India (UGC-ref. no. 223/NET- Dec. 2008).

\section{References}

1. International Institute for Population Sciences (IIPS) \& ORC MACRO: National Family Health Survey (NFHS -3), 2005-06: India Mumbai: International Institute for Population Sciences 2007: Vol I.

2. Ramalingaswami V, Johnsson U, Rohde J. The Asian Enigma. Progress of Nations. New York: United Nations Children's Fund 1996.

3. Gragnolati M, Shekar M, Das Gupta M, Bredenkamp C, Lee YK. India's Undernourished Children: A Call for Reform and Action". Health, Nutrition and Population Discussion Paper, World Bank 1996.

4. UNICEF (United Nations Children's Fund): Strategy for Improved Nutrition of Children and Women in Developing Countries. New York. United Nations Children's Fund 1990.

5. Svedberg P. Child Malnutrition in India and China. 2020 focus brief on the world's poor and hungry people. International Food Policy Research Institute 2007.

6. Mariam C, Eduard R. Bos, Tazim M. Indra Pathmanathan, Reducing child mortality in India in the new millennium. Bulletin of World Health Organization 2000; 78: 1192-9. 
7. Mittal PC. \& Srivastava S. "Diet, nutritional status and food related traditions of Oraon tribes of New Mal (West Bengal), India." Rural and Remote Health 2006; 6 (1): 385.

8. Topal, YS \& Samal, PK. "Causes for variation in social and economic conditions among tribes of Indian Central Himalaya: A comparative study." Man in India, 2001; 81: 87-8.

9. World Health Organization. Physical status: the use and interpretation of anthropometry. Technical Report Series No. 854. Geneva: World Health Organization 1995.

10. Bisai S. Nutritional Status and Growth pattern of Urban Infants in Relation to Birth weight. Current Science 2008; 95: 175.

11. Cole TJ, Flegal KM, Nicholls D and Jackson AA. Body mass index cut offs to define thinness in children and adolescents: international survey. British Medical Journal 2007; 335; 194-8. http://dx.doi.org/10.1136/bmj.39238.399444.55

12. Cole TJ, Bellizzi MC, Flegal KM and Dietz WH. Establishing a standard definition for child overweight and obesity worldwide: international survey. British Medical Journal 2000; 320; 1-6. http://dx.doi.org/10.1136/bmj.320.7226.1
13. de Onis M, Onyango AW, Borghi E, Siyam A, Nishida C, Siekmann J. Development of a WHO growth reference for school-aged children and adolescents. Bulletin of the World Health Organization 2007; 85:660-7. http://dx.doi.org/10.2471/BLT.07.043497

14. Bose K, Bisai S, Mukherjee S. "Anthropometric characteristics and nutritional status of rural school children", Internet Journal of Biological Anthropology 2008: Vol 2, No: 1.

15. Bose K, Bisai S. "Prevalence of undernutrition among rural adolescents of West Bengal, India", Journal of Tropical Pediatrics 2008:54: 422-3. http://dx.doi.org/10.1093/tropej/fmn044

16. Chakraborty R, Bose K. "Very high prevalence of thinness using new international body mass index cut off points among 5-10 year old school children of Nandigram, West Bengal, India", Journal of Research in Medical Sciences 2009: 14: 129-33.

17. Medhi GK, Hazarika NC, Mahanta J. "Nutritional Status of adolescents among tea garden workers", Indian Journal of Pediatrics 2007: 74: 343-7. http://dx.doi.org/10.1007/s12098-007-0057-3 